\title{
IMAGEN DE APOLO EN CALIMACO (HIMNO II) Y EN TIBULO (II 5)
}

\begin{abstract}
The author makes a comparative study of Apollo's image in Callimachus' hymn II and in the fifth elegy of Tibullus' book II.
\end{abstract}

El segundo de los himnos de Calímaco de Cirene está dirigido a Apolo, el más bello y brillante de los hijos de Zeus, dios de la luz. Su situación dentro del corpus de himnos calimaqueos obedece a motivaciones de indole dialectal. Los himnos I-IV están escritos en dialecto épico-jónico; V y VI, en un dorio literario, análogo al empleado por Teócrito. Los cuatro primeros y el último se sirven del hexámetro; el quinto, Al baño de Palas, utiliza el esquema métrico elegíaco. Zeus, Artemis, Delos y Deméter son los destinatarios de los himnos I, III, IV y VI, respectivamente.

El libro II de elegías de Albio Tibulo comprende seis composiciones, probablemente situadas en orden cronológico: se escalonarian entre los años 24 (ó 23) y 19 antes de Cristo. La primera elegía es una pieza rústica sobre la que se injerta un motivo elegíaco. La segunda celebra el cumpleaños de Cornuto, un amigo del poeta. La tercera, la cuarta y la sexta giran en torno a una pasión amorosa, la de Tibulo por una bella cortesana, llamada con el nombre ficticio y grandilocuente de Némesis. La quinta va dirigida a Marco Valerio Mesalino, hijo mayor de Mesala, con motivo de haber sido elegido quindecimuir sacris faciundis et Sibyllinis libris inspiciundis. Tibulo invoca en esta circunstancia a Apolo, dios de los oráculos, dispensador de la prosperidad de los campos, iniciador en el difícil arte de predecir lo por venir, de reconocer los signos de cólera de los dioses y de conjurar en lo posible su hostilidad, guardián de los libros proféticos e inspirador de las verídicas Sibilas, en particular de la Sibila de Cumas, cuya predicción había sido el primer beneplácito divino de la grandeza romana. El poeta ha con- 
vertido su elegia en un auténtico himno en honor de Febo Apolo, asociándose con una fe sincera, y no circunstancial, a uno de los cultos griegos más importantes que fueron trasplantados a Roma.

Así, pues, dos poetas, Calímaco y Tibulo, con dos siglos largos de intervalo entre ellos, acometen la muy sagrada tarea de celebrar a Apolo. Muy probablemente, Tibulo conoció el himno calimaqueo. Tengamos en cuenta que los vates del círculo de Mesala, aunque una generación más jóvenes que los poetae noui, se hallaban sobremanera influidos por el quehacer alejandrino, además de estar sometidos a la férula tierna y melancólica del Mantuano.

El himno II de Calímaco es una composición llena de vigor patriótico y religioso. Se afirma en él la fe de los cireneos en la protección de su divino patrono, y su lealtad para con la dinastía egipcia, cuya autoridad está fortalecida por la palabra misma del dios. La lista completa de los atributos de Apolo mencionados en el poema es la siguiente:

\section{HIMNO II DE CALIMACO 1}

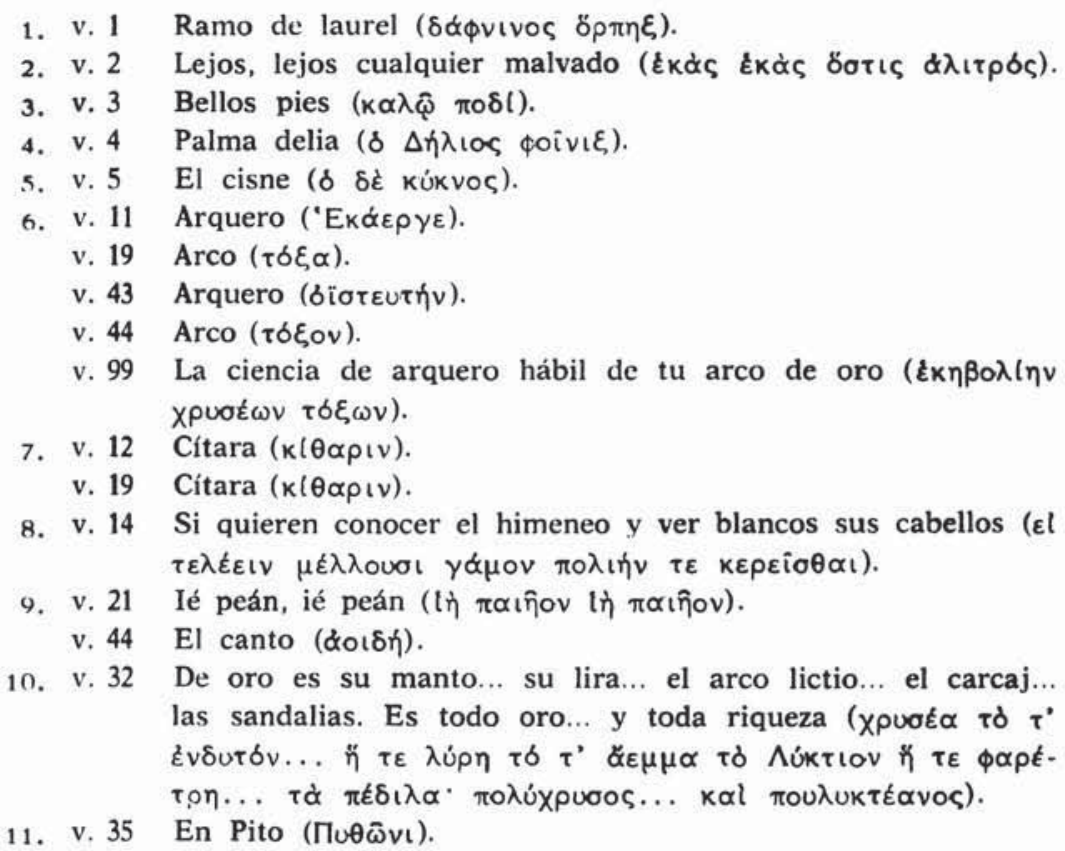

1 Ed. R. Pfeiffer, Oxford 1953. 


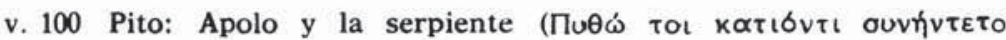

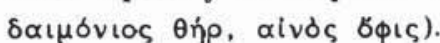

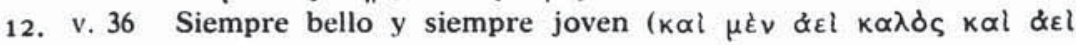
véos).

v. 37 Ningún bozo (

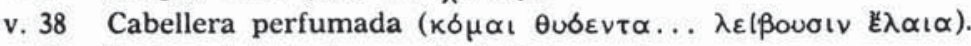

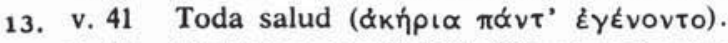

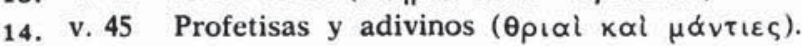

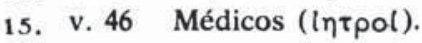

16. v. 47 Protector de pastores y rebaños. Apolo y Admeto (No $\mu$ เo $)$ ).

17. v. 55 Patrono de la fundación de ciudades $\left(\Phi_{\circ}\left(\beta \omega \delta^{\prime} \dot{\varepsilon} \sigma \pi \delta \mu \varepsilon v o\right.\right.$ ।

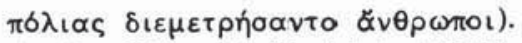

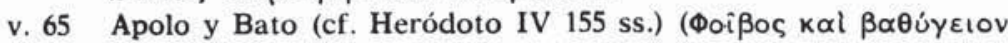

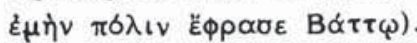

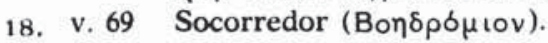

19. v. 70 Clario (de Claros, ciudad de Jonia) (K入\&pıov).

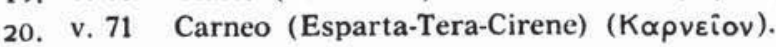

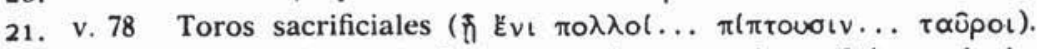

v. 80 Altares llenos de flores en primavera, de azafrán en invierno

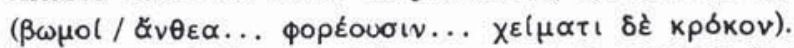

22. v. 83 Brille para ti siempre el fuego que no se extingue ( $\& \varepsilon l \delta \varepsilon$ to ¿દ́v $\propto$ ov $\pi \hat{p})$.

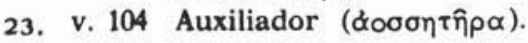

La pieza está escrita, sin lugar a dudas, para la fiesta de Apolo Carneo en Cirene. En Lacedemonia, Apolo era venerado como Kapveîos (equiparado a Carno, antiguo dios dórico de la fecundidad). En la propia Esparta las fiestas Carneas se identificaban y confundían con las Hiacintias; en Atenas se denominaban Targelias; en Delos, Delias. Fueron dorios los colonizadores de Cirene. Procedían de Tera, donde fue venerado también un Apolo Carneo procedente de Esparta (vv. 7273). Bato-Aristóteles viene a ser el responsable humano de la fundación de Cirene; Apolo, el responsable divino. El episodio lo refiere Heródoto en el pasaje arriba citado.

En la elegía V del libro II de Tibulo, el Apolo predominantemente invocado se corresponde en el himno calimaqueo con nuestro atributo 14, el Apolo patrono de profetisas y adivinos: basta con darse cuenta de la intención y del destinatario del poema. El esquema de la elegía es, para lo que aquí nos interesa, el siguiente: 


\section{ELEGIA II 5 DE TIBULO 2}

1. v. 2 cum cithara carminibusque ueni.

2. v. 4 nunc precor ad laudes flectere uerba meas.

3. v. 5 triumphali deuinctus tempora lauro.

v. 63 sic usque sacras innoxia laurus / uescar.

v. 81 et succensa sacris crepitet bene laurea flammis.

v. 83 laurus ubi bona signa dedit.

v. 117 lauro deuinctus agresti.

4. v. 7 sed nitidus pulcherque ueni.

5. v. 8 longas... comas.

v. 121 sic tibi sint intonsi, Phoebe, capilli.

6. v. 11 tu procul enentura uides, augur.

v. 13 tuque regis sortes... haruspex.

v. 15 Sibylla.

Se sigue la narración del oráculo de la Sibila a Eneas (compárese Bato / Cirene / Pitia con Eneas / Roma / Sibila), en la que se inserta un paréntesis blando y bucólico, típicamente tibuliano (vv. 23-38). En el oráculo, alusión al Sol, v. 60: Solis anhelantes abluit amnis equos. Sólo otra alusión al carácter solar de Apolo en vv. 75-76:

$$
\begin{gathered}
\text { ipsum etiam Solem defectum lumine uidit } \\
\text { iungere pallentes nubilus annus equos. }
\end{gathered}
$$

En los vv. $67-70$ se refiere Tibulo a una serie de adivinadoras inspiradas por Apolo:

v. 67 Amalthea: Sibila de Cumas en Tibulo.

v. 67 Marpesia... Herophile: sacerdotisa de Apolo Esminteo (de Esminta, en la Tróade), intérprete de sus oráculos. El monte Marpesa, en la isla de Paros.

v. 68 Phyto (sic) Graia: Delfos.

v. 69 Aniena... Tiburs: Sibila de Tíbur o Tívoli. El río Anio (= Teverone o Aniene) explica el sobrenombre.

7. v. 83 gaudete coloni... (v. 83 ss.: insiste en el Apolo protector de los campos, en el Apolo Nó $\mu$ ıos de Calímaco).

v. 89 ille leuis stipulae sollemnis potus aceruos / accendet, flammas transilietque sacras (vv. 89-90: sacrificios rituales del labrador). A continuación, un cuadro campestre muy tibuliano: dulzón, melancólico y sensual (vv. 91-104).

8. v. 105 pace tua pereant arcus pereantque sagittae, / Phoebe, modo in terris erret inermis Amor. / ars bona: sed postquam sumpsit sibi tela Cupido... (vv. 105-107). En Tibulo el carcaj y las flechas

2 Ed. M. Ponchont, Paris 1968. 
de Apolo adquieren un tono menor: Cupido se ha apoderado de tan funestas armas, lo que facilitará una expansión intimista de signo suave y delicadamente dolorido (vv. 109-112).

9. v. 113 nam diuum seruat tutela poetas.

10. v. 118 «io!" magna uoce "triumphe» canet.

El Leitmotiv del poema, completamente ajeno a la pura y simple glorificación del dios, aparece en v. 115: ut Messalinum celebrem, para reaparecer con la alusión al padre del agasajado en v. 119: tunc Messalla...

El final de la elegía es de una modernidad increíble. Del comportamiento de Apolo para con el poeta -en un sentido, claro está, figurado- dependerá la permanente longitud de sus cabellos, incluso la eterna castidad de su cinegética hermana (vv. 121-122).

Dos esquemas, dos mundos, un préstamo directo (de Calímaco a Tibulo), superioridad del alejandrino sobre el romano en cuanto a información acerca de la divinidad que nos ocupa (no en vano es invocado con frecuencia el autor de los Aetia en los manuales de mitología): tales son las evidencias después del análisis. En nuestra numeración no cabe la más mínima sospecha acerca del mayor número de datos suministrados por el bibliotecario-poeta: veintitrés frente a diez, siempre con la posibilidad de sintetizar más. El oficialismo calimaqueo se compensa con el escapismo lírico, no exento de una buena dosis de fe y patriotismo, de Tibulo. Todo esto salta a la vista, no necesita demostración. En cuanto a Apolo, y en líneas muy generales, ¿qué perfil -lo más delimitado posible- presenta en los tratados al uso? Esbozado éste, podrían compararse los dos Apolos propuestos por los dos poetas. Atendiendo tan sólo a Calímaco (himno II) y a Tibulo (II 5), las características míticas del dios, encuadradas en su tipología más extendida, son las siguientes:

- Nos referiremos fundamentalmente al Apolo griego. Su homónimo romano era venerado como dios profetizador y dios de la salud (Tibulo 6). En 429 antes de Cristo se erigió en Roma el primer templo de Apolo, con ocasión de una grave pestilencia. Augusto, en agradecimiento por la victoria de Accio, levantó un templo en el Palatino en el que se veneraba la famosa estatua de Apolo Citaredo, de Escopas. Queda clara, pues, la sincera fe del poeta dentro de su elegía, producto del momento histórico en que la compuso. 
- Hijo de Zeus y Leto. Ésta le dio a luz en la isla de Delos (Calímaco 4), adonde se había dirigido perseguida por el odio de la celosa Hera. De un mismo parto nacieron Artemis y Apolo (Tibulo, v. 122).

- Dios del cielo, luminoso combatidor de los poderes de las tinieblas (Calímaco 2, 22) con sus flechas infalibles (Calímaco 6, Tibulo 8). Mata a Pitón (Calímaco 11), a Ticio, a los Nióbidas. Personifica la potencia del sol primaveral que vence a los oscuros poderes del invierno (Tibulo 6, v. 60 ).

- Pero el sol es también una fuerza destructora. Así, el hijo de Leto es conductor de la muerte (Hiacinto y Apolo, comienzos de la Ilíada, etcétera).

- Cuando Zeus intentó arrojar al Tártaro a su hijo Apolo, después que éste exterminara a los Cíclopes para vengar a Asclepio, Leto intercedió por él. Apolo hubo de peregrinar un año por la tierra como esclavo. Fue pastor de ovejas del rey de Feras, Admeto, en las laderas del Pelión. Surgió entre ambos una íntima y cordial amistad. El dios consiguió que el monarca pudiera conservar la vida y no morir nunca, siempre que alguien se ofreciera a descender al Hades en su lugar. Alcestis se ofreció, pero eso es ya otro mitologema. (Alusión a Admeto / Apolo en Calímaco 16).

- Entroncado con la leyenda del rey de Feras se encuentra un nuevo atributo apolíneo: Febo protector del crecimiento de las plantas en las praderas, Apolo Nóuıos, patrono de la ganadería y de la agricultura. Posee ganados de bueyes (robados y devueltos por Hermes). Aristeo, divinidad menor de las faenas agrícolas, es hijo suyo. En las inmediaciones de Esparta se venera a Apolo como Kapveîos, equiparado al dios dorio Carno, como apuntábamos arriba. Para Nópıos, Calímaco 16, Tíbulo 7. Para Kapveíos, Calímaco 20.

- Como hemos visto, puede enviar la muerte. Pero también puede alejarla, si se le ofrecen los debidos sacrificios (Calímaco 21, Tibulo 7,

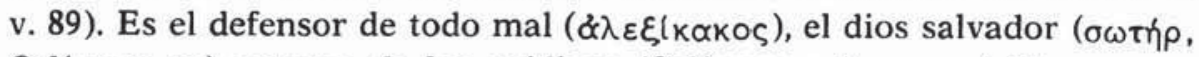
Calímaco 23) patrono de los médicos (Calímaco 15) - no olvidemos que Asclepio pasa por ser hijo suyo- Como divinidad protectora, proporciona ayuda decisiva en las batallas ( $\beta$ $\rceil \delta \rho \delta \mu \iota \varsigma$, Calímaco 18). Representa un principio natural de salud (Calímaco 13).

- Dios de los juramentos. Se venga de los perjuros.

- Adscrito a funciones purificadoras y expiatorias ( El fuego purificador se obtenía frotando dos trozos de madera de laurel

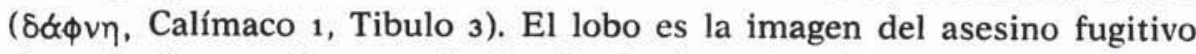
al cual ofrece asilo y expiación Apolo. Laurel y lobo (Apolo $\lambda$ úkı́s o

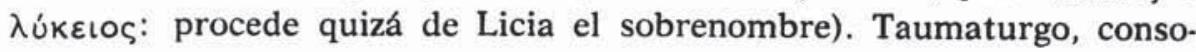


lador por excelencia. En Calímaco, v. 19, no incluido en nuestra nume-

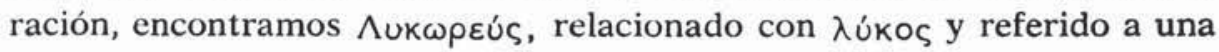
de las cumbres del Parnaso.

- Dios de la música. Su instrumento favorito es la cítara o $\phi \delta ́ \rho \mu \iota \gamma \varepsilon$ (Calímaco 7, Tibulo 1). Caudillo y patrono de las Musas (Musagetes). Protector de los poetas y cantores (Tibulo 9). Su lira deriva del arco, debido a que se había observado la sonoridad de las cuerdas tensas de aquél, arma favorita del dios (Calímaco 6, Tibulo 8). $\Delta \varepsilon \lambda \phi$ (vios lo llaman los marinos, por la supuesta sensibilidad del delfín hacia la música. Modula los cantos (Tibulo 1, 2). Se le invoca con un grito especial (Calímaco 9, Tibulo 10).

- Es, sobre todo, la divinidad de las profecías y los oráculos (Calímaco 14, Tibulo 6). Como dios vidente, y siguiendo al autor del himno homérico a Apolo, poseía santuarios en Colofón (Claros, Calímaco 19), Dídima en Mileto, Ismeno cerca de Tebas, Pátara y Janto en Licia, Delos, Delfos, lugares sagrados al pie del monte Cinto..., allí donde llegó la colonización griega. En Delfos, la Pitia (Tibulo 6) masticaba hojas de laurel (Calímaco 1, Tibulo 3) después de beber de la fuente Castalia. Luego se colocaba sobre el sagrado trípode, situado en una hendidura de la tierra ( $\sigma \tau \delta \dot{\mu \iota}$ ○ $\gamma \hat{\eta} \varsigma$ ).

- Dios nacional del pueblo jonio y guía en sus emigraciones coloniales ( $\pi \alpha \tau \rho \hat{Q} \circ \varsigma, \alpha \rho \chi \eta \gamma \varepsilon \tilde{\tau} \eta$, Calímaco 17).

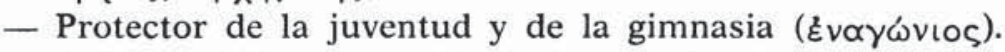

- Antropomórficamente, Apolo es un joven fuerte y hermoso (Calímaco 12, Tibulo 4). Sin barba, pero con largos y ensortijados cabellos (Calímaco, indirectamente, v. 38; Tibulo 5). Se le suele representar desnudo y recio, con un manto o clámide echado sobre los hombros o en el brazo izquierdo, como en la figura central del frontón oeste del templo de Zeus en Olimpia. Sus vestiduras son siempre paradigma de riqueza (Calímaco 10) cuando aparece como Musagetes, con amplias ropas de citaredo - veste jonia larga o jitón-, coronado de laurel y con una lira, como el archifamoso Apolo de Escopas que poseyera Augusto. Otras veces aparece con arco y carcaj. En ocasiones, portando la égida (Iliada XV), como el conocido Apolo de Belvedere. Praxíteles le convierte en un afeminado matador de lagartos con rasgos adolescentes, los mismos que encontramos en el Apollino de los Uffizi, admirable interpretación que no invita a considerar al dios en su majestad, como hijo más brillante de Zeus con las prerrogativas que ello comporta (el imprescindible Apolo de Calímaco 8). El poeta de Cirene nos habla, además, de una divinidad de hermosos pies (Calímaco 3 ).

LI, $1 .^{\circ}-10$ 
- Entre los atributos cotidianos de Apolo se cuentan arco y flechas (sus dardos siempre alcanzan el blanco, es «el que alcanza en la lejanía", Calímaco 6), carcaj o faretra, corona de laurel, forminge o cítara, trípode y ónfalos (como el existente en Delfos, destinado a que el dios se siente sobre él).

- Entre los animales a él consagrados citaremos el lobo, el ciervo, el cisne (Calímaco 5) y el delfín.

Karl Kerényi ha definido a Apolo como "aquel dios que purifica de todo lo mortal o que aniquila lo impurificable» ${ }^{3}$. Sólo el hijo de Zeus y Leto es digno de llevar, con todas las consecuencias, el adjetivo öøı al lado. Calímaco y Tibulo nos han dado dos visiones del dios. La del poeta cireneo, que es la del portavoz político y religioso, nos resulta tal vez excesivamente "apolínea" - por decirlo así- y ortodoxa. En Calímaco, Apolo representa el dominio de sí mismo, el respeto a la autoridad, la mística de la masculinidad, la consciencia de lo divino y tantas otras virtudes délficas. La visión de Tibulo, como contraste, nos ofrece el triunfo de otra divinidad, ésta cercana, pasible, el Amor, quien, con el celestial permiso de Febo, se ha apoderado de su arco y de sus mortíferas flechas e, inconsecuente siempre y arbitrario, pasea desde entonces su figura, en prepotente soledad, por la ojerosa faz de la tierra.

Luis Alberto de Cuenca

3 La religión antigua, trad. esp., Madrid 1972, p. 88. 